\title{
Jesuítas na İndia portuguesa: a expulsão dos nativos do Colégio de Goa (1548-1551)
}

\author{
Jesuits in portuguese India: the expulsion of Goa College natives (1548-1551)
}

\author{
Felipe Augusto Fernandes Borges* \\ Instituto Federal do Paraná (IFPR), Pitanga, PR, Brasil \\ Sezinando Luiz Menezes** \\ Universidade Estadual de Maringá (UEM), Maringá, PR, Brasil \\ Célio Juvenal Costa*** \\ Universidade Estadual de Maringá (UEM), Maringá, PR, Brasil
}

\begin{abstract}
RESUMO: Goa era a capital do Estado da Índia, sendo, ao mesmo tempo, o centro de administração civil, política e religiosa dos portugueses naquelas partes. O Seminário de Santa Fé foi fundado em Goa em 1541. O objetivo do Seminário era formar um clero nativo indígena. A partir de 1546, o Seminário foi entregue à responsabilidade da Companhia de Jesus. Em 1548, os jesuítas dividiram a instituição em duas, fundando o Colégio de São Paulo. O recorte temporal desta pesquisa situa-se entre os anos de 1548 e 1551, quando o jesuíta António Gomes desempenhou o cargo de reitor, promovendo a expulsão dos nativos do Colégio de São Paulo. Pretendemos compreender a dinâmica desse processo, as motivaçóes do padre Gomes para tal ação, seu impacto em Goa e, ainda, o movimento de reversão de tal medida. Entendemos que, ao impor a expulsão dos nativos do Colégio, Gomes se opôs ao projeto de formação de um clero indígena que ele representava: projeto esse que já havia sido incorporado e bem aceito pelas autoridades civis e religiosas em Goa e mesmo no Reino. As fontes documentais utilizadas neste trabalho estão contidas nos volumes I e II da Documenta Indica, organizados pelo padre jesuíta Joseph Wicki.
\end{abstract}

PALAVRAS-CHAVE: Colégio de São Paulo. Seminário de Santa Fé. Companhia de Jesus. Clero indígena. Goa.

\footnotetext{
*Doutor em História e professor do Instituto Federal do Paraná (IFPR), Campus Pitanga.

E-mail: felipe. borges@ ifpr.edu.br.ORCID: https://orcid.org/0000-0002-4812-9992.

**Doutor em História e professor da Universidade Estadual de Maringá (UEM). E-mail: sl.menezes@uol.com.br. ORCID: https://orcid.org/0000-0002-1518-0783.

*** Doutor em Educação e professor da Universidade Estadual de Maringá (UEM).

E-mail: celiojuvenalcosta@gmail.com. ORCID: https://orcid.org/0000-0003-1226-7805.
} 
ABSTRACT: Goa was the capital of the State of India, being, at the same time, the center of civil, political and religious administration of the Portuguese in those parts. The Seminary of Santa Fe was founded in Goa in 1541. The purpose of the Seminary was to form a native indigenous clergy. From 1546 the Seminary was given to the responsibility of the Society of Jesus. In 1548, the Jesuits divided the institution into two, founding the College of São Paulo. The time frame of this research is between the years 1548 and 1551, when the Jesuit António Gomes held the position of rector, promoting the expulsion of the natives of the College of São Paulo. We intend to understand the dynamics of this process, the motivations of Father Gomes for such action, its impact on Goa and, also, the movement of reversal of such measure. We understand that by imposing the expulsion of the natives of the College, Gomes opposed the project of formation of an indigenous clergy that he represented: a project that had already been incorporated and well accepted by the civil and religious authorities in Goa and even in the Kingdom. The documentary sources used in this work are contained in volumes I and II of Documenta Indica, organized by jesuit priest Joseph Wicki.

KEYWORDS: College of São Paulo. Santa Fe Seminary. Society of Jesus. Indigenous Clergy. Goa.

\section{Introdução}

A presença portuguesa na Índia, de maneira contínua e regular, iniciou-se com a instauração da "Rota do Cabo", feito alcançado por Vasco da Gama em 1498. A partir de então, houve um progressivo desenvolvimento do que, anos depois, seria chamado de "Estado da Índia": o conjunto de territórios, estabelecimentos (feitorias, fortalezas...), bens, pessoas, interesses, comércio e mesmo a Igreja, todos administrados pela Coroa Portuguesa, nos espaços do "Oceano Índico e mares adjacentes, ou nos territórios ribeirinhos, do cabo da Boa Esperança ao Japão" (THOMAZ, 1994, p. 207). Pela instituição do Padroado Régio, a Igreja acompanhava sempre a expansão portuguesa, levando padres, irmãos e missionários a evangelizar os diferentes espaços em que a empresa lusitana chegava. A empresa comercial e a empresa religiosa andavam juntas, como plasmado na conhecida frase do padre Antônio Vieira: "Os pregadores levam o Evangelho, e os mercadores levam os pregadores” (VIEIRA, 1953 Apud BOXER, 2002, p. 80). Com o desenvolvimento paulatino do Estado da Índia e a crescente necessidade - sentida por parte dos colonizadores - de catequização das gentes orientais, a formação de padres para tal tarefa passa a ser premente.

Goa foi conquistada por Afonso de Albuquerque, então Governador Geral da Índia, em 1510, tomada das possessóes do sultão de Bijapur (TAVARES, 2004). A cidade, importante porto na região, tornou-se capital do Estado da Índia, sendo, ao mesmo tempo, o centro de administração civil, política e religiosa dos portugueses naquelas partes.

Goa tornar-se-ia, ao longo dos anos da administração portuguesa, uma cidade repleta de igrejas, conventos, colégio e casas religiosas. Como centro irradiador da administração portuguesa, de lá, saíam todas as decisões e políticas para aquelas possessóes (BORGES, 2018).

As primeiras tratativas para a fundação de um seminário cristão na Índia remontam à década de quarenta do século XVI, que apresentou, na Índia, e, especialmente, em Goa, uma viragem política da presença portuguesa. Até então, havia certa tolerância religiosa para com a população hindu, entretanto, a partir de 1540, ocorreu no Oriente Português o desenvolvimento de uma forte intolerância religiosa cristã, e é nesse contexto que surgiram a Confraria de Conversão à Fé, bem como o Seminário de Santa Fé. O Seminário de Santa Fé foi fundado em Goa no ano de 1541, tendo suas atividades se desenvolvido, a partir de 1542, com a participação de padres da Companhia de Jesus. O desenvolvimento das atividades do Seminário - que tinha o objetivo de 
formar um clero nativo indígena - deu-se com o auxílio e a presença cada vez maior dos jesuítas, de forma que, a partir de 1546, o Seminário foi inteiramente entregue a eles. A partir de 1548, os jesuítas dividiram a instituição em duas, fundando o Colégio de São Paulo.

As fontes documentais utilizadas neste trabalho estão contidas nos volumes I e II da Documenta Indica, organizados pelo padre jesuíta Joseph Wicki. O recorte temporal, por sua vez, situa-se especificamente entre os anos de 1548 e 1551, quando o jesuíta António Gomes desempenhou o cargo de reitor, promovendo a expulsão dos nativos da instituição. Nossa proposição, aqui, é compreender a dinâmica desse processo, as motivações do padre Gomes para tal ação, seu impacto em Goa e, ainda, o movimento de reversão de tal medida. Vale lembrar a gravidade da expulsão dos nativos, uma vez que a instituição em tela havia sido criada, já em seu princípio, com o claro objetivo de formação de um clero nativo: ao proceder em sua decisão, António Gomes estava, diretamente, subvertendo a finalidade do Colégio que agora presidia.

Com relação às nossas fontes, devemos tecer algumas observações. As fontes utilizadas para as reflexões deste trabalho são, em grande parte, constituídas por cartas jesuíticas. Além disso, estão contidas em uma coletânea, organizada e comentada por um historiador que, além desse ofício, é também um religioso, um jesuíta. O que desejamos pontuar é que os documentos e as cartas apresentam visões de homens, em sua maioria religiosos, jesuítas, que estavam comprometidos com as finalidades inerentes à missão catequética na Índia Portuguesa. Ademais, a maneira de organização dessas cartas, em forma de coletânea, remonta a escolhas, seleções e organização dos documentos, de acordo com critérios próprios do organizador.

$\mathrm{Na}$ esteira dessas reflexóes, dois trabalhos devem ser aqui mencionados também como condutores em nosso processo de análise das fontes. O primeiro, de Pécora (2008), e o segundo, de Lodoño (2002).

Em seu artigo, Pécora faz uma análise dos cinco momentos formais que compóem as cartas dos padres da Companhia de Jesus. Baseados na "ars dictaminis", ou seja, na "arte de escrever cartas", os inacianos, segundo Pécora, tinham claros os cinco momentos principais daquela, quais sejam, "salutatio, captatio benevolentiae, narratio, petitio e conclusio" (PÉCORA, 2008, p. 39-40). Toda essa metalinguagem, implícita nas cartas jesuíticas, tinha como objetivo principal captar a atenção do leitor para a missão religiosa. Fossem os leitores leigos ou mesmo superiores religiosos, o intuito das cartas era despertar naqueles o desejo de fazer o possível para auxiliar nas missões. Já Lodoño, analisa as cartas jesuíticas, mostrando, sobretudo, o caráter de intencionalidade delas. $\mathrm{O}$ autor afirma com relação às cartas dos jesuítas que "[...] uma boa parte das cartas teria sido produzida com o propósito claro de edificar [...]”, ou seja, o autor destaca que tal escrita “[...] apontava para as ações que serviam para manifestar a presença divina, estimular a Fé do próximo e infundir piedade”. As cartas estavam determinadas pela sua função, seus destinatários e objetivos particulares (LODOÑO, 2002, p. 12). As questôes, os posicionamentos e as advertências propostas pelos autores citados, com relação às cartas jesuítas, permeiam nosso olhar sobre elas, além do que entendemos ser importante estender tais cuidados às demais fontes também, mesmo que não sejam todas originárias de membros da Companhia de Jesus. 


\section{0 governo do reitor António Gomes e a expulsão dos nativos do Colégio de São Paulo}

O "problema" dos cleros nativos esteve presente nas missões do Ultramar desde muito cedo. Debates e diferentes posições tiveram lugar dentro das missões, e também especificamente dentro das missões da Companhia de Jesus. Há na historiografia (mais antiga e mais recente) autores que apontaram características e problematizaram a relação da Companhia de Jesus com cleros nativos, alguns dos quais apresentamos a seguir. O caso de António Gomes e da expulsão dos nativos do Colégio de São Paulo certamente é um dos exemplos que merece uma discussão dentro do contexto dos cleros nativos.

O jesuíta António Gomes chegou à Goa no mês de outubro de 1548, enviado por Simão Rodrigues para ser reitor do Colégio de São Paulo (ALBUQUERQUE, 1548, s.p. Apud WICKI, 1948, p. 303). Pela relevância que alcançou em sua atuação no Oriente português, convém apresentarmos alguns detalhes sobre António Gomes. O novo padre reitor "Era membro de uma família de posses na Ilha da Madeira, mestre em artes, doutor em teologia e especialista em direito canônico" (SANTOS, 2007, p. 53). Sua formação e sua eloquência nas pregações logo chamaram a atenção da população de Goa, tanto do povo comum quanto dos nobres e das autoridades locais. Ao que aparentam suas cartas, decisóes que tomou e mesmo relatos de outras pessoas sobre ele, seria uma pessoa firme, insistente e decidida em suas convicções. Veremos que talvez algumas dessas características tenham sido responsáveis por lhe render alguns reveses na missão oriental.

Xavier (2008) refere-se ao padre António Gomes e à situação de expulsão dos nativos aqui debatida, colocando-a sob uma perspectiva ampla. A autora aponta que os portugueses em Goa, àquela altura, passavam de um otimismo antropológico a uma atitude de descrença das qualidades das populações locais. Nesse movimento, insere a atitude de Gomes no contexto de perseguição das religióes locais, agravada por volta da década de quarenta do século XVI, que atingiria seu ápice, para a autora em tela, perto da década de sessenta do mesmo século, fato corroborado pela instalação da Inquisição naquelas partes. Assim, compreendemos que, para essa autora, a relação da Companhia de Jesus com o clero nativo, em Goa, perpassa as políticas e a cultura de discriminação sistemática dos não cristãos.

Županov trata especificamente da carreira de António Gomes como missionário na Índia. Ao citar a entrega completa da administração do Colégio aos jesuítas, feita pelos mordomos da Confraria de Santa Fé, a autora aponta que tal ação terminou com um "golpe de estado" (2005, p. 140), com Gomes transformando o que era uma instituição voltada e pensada para os nativos em um colégio jesuíta, uma "Coimbra indiana”, para usar a expressão da autora. Županov (2005) corrobora nosso posicionamento, apontando que António Gomes destacou, em suas cartas, que alguns nativos tinham entrado e tentado os exercícios espirituais, mas, para o padre, não mostravam "fruto". De acordo com a autora, mesmo dentro da Companhia, havia opinióes conflitantes com as de Gomes, citando como exemplo o padre Cosme de Torres, que via em alguns nativos um "desenvolvimento" que parece não ser observado por Gomes.

Os trabalhos de Tavares (2007; 2011) e Faria (2007) analisam, na perspectiva do século XVII, um problema que se afigurou na relação entre o clero europeu e o nativo na Índia Portuguesa: o papel subalterno a que o primeiro relegava o segundo. Tal perspectiva já fora problematizada por Boxer (2013). Faria (2007) faz sua análise com ênfase no caso específico de um clérigo nativo 
chamado Mateus de Castro. Tavares (2007) analisa a trajetória do mesmo padre, mas insere também o caso de outro nativo, José Vaz. No segundo trabalho citado, Tavares (2011) faz a análise da disputa por colocações e cargos de destaque alargando o recorte temporal para os séculos XVII e XVIII. As autoras convergem na interpretação de que era rara e dificultosa a mobilidade desse clero nativo para cargos e posições de prestígio, normalmente reservados aos nascidos em Portugal.

Nesse sentido, há também um trabalho mais recente, em que Gomide afirma, tendo como base um documento escrito em 1588 pelo visitador jesuíta Alessandro Valignano, em que consta "Classificar e hierarquizar os indivíduos eram assim, um ato concreto do jesuíta, no qual buscava desqualificar os filhos de portugueses e de portuguesas nascidos na Índia, considerados por ele, frutos de uma má qualidade da terra asiática” (GOMIDE, 2016, p. 34). No referido documento, citado pela autora em tela, o visitador recomendava ao Provincial da Índia que não recebesse nativos, mestiços ou castiços na Companhia (quanto aos nativos, faz exceção aos japoneses). Isso vem ao encontro do trabalho de Lacerda, em que a autora analisa os cleros nativos no contexto do Padroado Português. Em certo momento, lemos a afirmação de que "Até à sua extinção no século XVIII, a Companhia de Jesus só admitiu um indiano entre as suas fileiras, o brâmane Pêro Luís, aceite em 1575" (LACERDA, 2016, p. 229). Ou seja, mesmo que admitissem a necessidade de um clero nativo - o que os jesuítas de maneira geral aceitavam - a historiografia e as fontes nos mostram que mesmo os defensores de tal necessidade impunham a estes padres nativos certos limites, certos lugares sociais, em claro desejo de que houvesse uma subserviência destes ao clero europeu.

Anjos (2019), Dias (2019) e Borges (2018) também apresentam trabalhos recentes que tratam especificamente do Colégio de São Paulo em Goa. Dias (2019) problematiza a concepção de uma ligação "quase natural" da Companhia de Jesus com a educação como meio para catequização, apontando para práticas franciscanas e investigando se poderiam estas ter influenciado as formas de missionação da Companhia de Jesus. Já Anjos (2019), analisa o trabalho dos jesuítas para com os meninos nativos no Colégio de São Paulo. Em seu trabalho, a autora cita a polêmica da expulsão dos nativos sob António Gomes, concordando com o posicionamento de Borges (2018). Para os autores, o reitor acreditava que os nativos não teriam as mesmas qualidades de devoção e contemplação dos alunos europeus, acreditando ainda que tais capacidades não teriam como ser desenvolvidas entre eles.

Passando para a análise direta de nossas fontes, vemos algumas das impressões iniciais do padre António Gomes sobre o Colégio de São Paulo e mesmo sobre as missões como um todo em ampla carta que escreve de Goa ao padre Simão Rodrigues, em vinte de dezembro de 1548 (GOMES, 1548, s.p Apud WICKI, 1948, p. 409-426). Na carta, Gomes diz que, ao chegar ao Colégio, encontrou como superior o padre Nicolau Lancelote, o qual, conforme ordem de Francisco Xavier, prontamente entregou-lhe o comando do Colégio (GOMES, 1548, s.p Apud WICKI, 1948 , p. 412). Havia, na casa, segundo conta Gomes, oitenta ou noventa moços, divididos de acordo com suas idades, que aprendiam a ler e escrever, no caso dos mais novos, e também Latim, ensinado, por dois mestres: "[...] hum portuges por nome Domingos, Irmam de casa, outro André canarym” (GOMES, 1548, s.p Apud WICKI, 1948, p. 411). Esse trecho é assaz importante por mostrar-nos um nativo lecionando Latim no Colégio de São Paulo: vejamos que a diferença marcada pelo padre é clara, um dos mestres é português, irmão da casa, enquanto o outro é canarim, termo que os portugueses usavam para designar a população natural de Goa. Interessantíssimo vermos como um natural da terra foi educado, cristianizado e depois se encontrava lecionando, 
numa demonstração de como o propósito da instituição estava, de certa forma, alcançando seus objetivos. Vale ressaltar que esse André Canarim era o mesmo André Vaz que, depois, em 1558, seria ordenado como o primeiro padre goês. Não é coincidência, portanto, que, na mesma carta, António Gomes escreva que explicou a Francisco Xavier que

[...] os nervos e força da Companhia, segundo a entençam do P. Ignatio e de Vossa Reverencia [Simão Rodrigues], nam eram outros que os colegios criados em spiritu e en letras, e que o que mais se pretendia laa [na Europa] era fazer-se colegios, onde se ynsinasem em spiritu e letras os que avyam de aproveitar ao mundo, e o que mais avyamos de pretender nestas partes era dilatar a Companhia por toda a Yndia, o que nam se podia fazer sem colegios; [...]. (GOMES, 1548, s.p Apud WICKI, 1948, p. 412-413)

A utilização de Colégios como centros formadores e como base de apoio para as missóes estava sendo testada, ainda em seu início, mas seus resultados já estavam sendo vistos e aprovados pelos superiores da Companhia de Jesus, segundo nos mostra o relato do padre Gomes. A ideia de fundar colégios e seminários que formassem "na letra e no espírito" estava sendo apreciada naquele momento, com vistas tanto a formar quadros para a Companhia de Jesus quanto a formar religiosos que, mesmo não recebidos na Companhia - dentro do recorte temporal desta pesquisa esta era a regra: não receber nativos na Companhia de Jesus -, poderiam auxiliar esses padres, principalmente com relação às suas populações de origem.

Um dos primeiros problemas levantados na narrativa do reitor António Gomes estava ligado exatamente a essa ideia de formar "nas letras e no espírito". O padre reitor parece não ter se agradado com as competências dos nativos internos do Colégio de São Paulo já na sua chegada. Considerando que Gomes chegou ao Colégio em outubro de 1548 e escreveu a carta a que agora nos referimos em dezembro do mesmo ano, dois meses foram suficientes para que o padre formasse sua opinião a respeito dos nativos internos. E essa opinião não foi das melhores. Em posicionamento sobre os nativos, escreve Gomes na missiva:

Antre elles há engenhos bons e boas yncrinações, mas nam há nenhum spiritu, nem consideraçam. [...]. Há dous ou tres delles que tomaram os Exercicios, mas muy pouquo proveito se seguio diso polos nam continuarem depois de saydos. [...] Trabalhey o mais que pude de reduzir tudo a ser conforme co[m o] colegio de Coimbra; mas pola espiriencia que tenho e polos custumes em que entam postos estes moços, os quaes nenhuma cousa sabem nem de mortificaçóes nem de spiritu, acho muita dificuldade en se fazer aquy a obra que eu sey que Vossa Reverencia quer e deseja que se faça [...] (GOMES, 1548, s.p Apud WICKI, 1948, p. 411-412)

Para Gomes, os nativos poderiam aprender o que se ensinava, poderiam até mesmo ser ordenados ao sacerdócio, mas estariam num grau sempre abaixo dos portugueses. O padre considerava os nativos, como ele mesmo escreveu, "fracos de espírito" e, podemos dizer, inferiores aos europeus. No trecho anteriormente exposto, Gomes chega a dizer a Simão Rodrigues que, com aquilo que tinha em Goa - ou seja, os alunos nativos -, seria muito difícil implementar no Colégio os mesmos moldes europeus. Além disso, podemos dizer que, a respeito do que consideravam ser uma inferioridade intelectual e cultural dos nativos, também Francisco Xavier concordava com Gomes, pois, segundo o relato do padre, 
Mais disto pratiquey com mestre Francisco, por me elle dizer que a gente da terra era a mais della de fraquos spiritus, e que sem termos portugeses se nam faria nada, porque os portugeses de cá nam se querem confesar a hum indio nem mistiço clerigo senam hé portugueses [...]. (GOMES, 1548, s.p Apud WICKI, 1948, p. 416)

Tudo isso vem ao encontro da análise que Boxer (2013) faz ao dizer que os cleros indígenas, formados no âmbito do Padroado Português, onde existiram, eram quase sempre relegados a uma categoria inferior, como meros auxiliares, subalternos aos padres europeus, sobretudo aos regulares. Posicionamento corroborado nesse trabalho por meio das análises feitas por Tavares (2007) e Faria (2007), anteriormente apresentadas. Aí reside também outro tipo de hierarquização do clero: o clero regular sentia-se superior ao clero secular, isso falando mesmo dos padres europeus. Sendo assim, a diferença era ainda maior com relação aos nativos, pois esses dificilmente - quase nunca - eram recebidos nas ordens regulares da Igreja. O clero nativo estava sendo formado, via de regra, para atendimento e conversão de suas próprias populações, como já viemos afirmando anteriormente. Entretanto, parece que, para António Gomes, nem mesmo esse papel dos futuros clérigos nativos a serem formados no Colégio de São Paulo estava muito claro. Esses posicionamentos do padre Gomes são importantes para entendermos o projeto que ele vinha planejando para o Colégio de São Paulo. O que ele queria, na verdade, era que o Colégio de Goa se tornasse uma espécie de escola superior, a receber apenas aqueles que já tivessem feito seus estudos de base em outros colégios que ele imaginava implantar, ou mesmo instrumentalizar alguns que já existiam para isso.

Nessa carta, o reitor António Gomes explica ainda que considerava a administração do Colégio de São Paulo difícil, por se haver muitos moços de diferentes idades e diferentes estágios: uns aprendendo a ler e escrever, outros aprendendo Gramática e Latim, outros, Artes e, outros, Teologia. A ideia apresentada pelo reitor era a de que o Colégio de São Paulo se concentrasse em ensinar apenas Artes e Teologia e que outros colégios fossem feitos, dando como exemplos as localidades de Chale e Cochim - onde já existiam colégios menores - e que lá se ensinasse a ler, escrever e Latim. Assim, depois de passar por esses colégios iniciais e visto nos jovens “capacidade para mais letras”, estes então seriam enviados para o Colégio de São Paulo, que seria como um colégio superior, nas palavras do reitor, "universidade de toda a India". Ali, como em Coimbra, os estudantes aprenderiam Artes, Teologia e os Exercícios Espirituais. Além disso, planejava que aqueles que não tivessem habilidades para cursar o Colégio de São Paulo seriam colocados em outros ofícios que não necessitassem de estudos superiores (GOMES, 1548, s.p Apud WICKI, 1948, p. 409-426).

Vemos que o projeto de António Gomes era usar o Colégio de São Paulo para formar, quase que exclusivamente, padres para a Companhia de Jesus. Assim, o projeto do reitor esbarrava no propósito inicial da fundação da casa que, como idealizado pelos confrades de Santa Fé, era formar nativos. Por conta disso, Gomes acabaria falhando na tentativa de colocar seu projeto em prática.

Antes de falarmos sobre a expulsão dos alunos nativos, há alguns outros pontos importantes a tocar, que aconteceram sob o governo de António Gomes no Colégio. Um deles é a autonomia financeira da instituição. Até a chegada de António Gomes, era Cosme Anes, vedor da fazenda real e confrade fundador da Confraria e do Seminário de Santa Fé, quem gerenciava os recursos da casa. Porém, o padre jesuíta Nicolau Lancelote, em carta enviada de Cochim ao Padre Geral, Inácio de Loiola, datada de 26 de dezembro de 1548 (LANCELOTE, 1548, s.p. Apud WICKI, 1948, p. 434-444), conta que "[...] Cosme Ianne, fondador del colegio, tutto se intrigo a lui [ao Padre António Gomes], dandogle plenaria autorità Del ditto coleggio, così nem temporale como 
nel spirituale [...]" (LANCELOTE, 1548, s.p. Apud WICKI, 1948, p. 439). Assim, desde a chegada de António Gomes como reitor, podemos dizer que, então, totalmente, o Colégio e o Seminário ficaram sob a guarda da Companhia de Jesus, tanto no que dizia respeito ao espiritual e pedagógico quanto às suas rendas e finanças.

$\mathrm{Na}$ continuidade dos relatos ao Geral, Nicolau Lancelote também pontua as mudanças que estavam sendo feitas por António Gomes no funcionamento do Colégio. Percebemos que, assim que chegou, o reitor procurou empregar uma forma de trabalho com os estudantes que considerava mais adequada. Dessa forma, escreve padre Lancelote:

[...] e subito che el ditti Antonio Gomez entrò in nel cargo del colegio comenzò a darghle nova forma in tutto, dicendo che voleva pore questi collegiali nel stilo parisiensi acerca a l'ordene del studiare, et cerca alla meditatione et oratione nella manera che acostumano li nostri in Coimbra, et al presente leva questo ordine. (LANCELOTE, 1548, s.p. Apud WICKI, 1948, p. $439-440)^{1}$

O reitor padre António Gomes estava implantando o modelo pedagógico conhecido como modus parisiensis. Esse modelo consistia em um conjunto de normas pedagógicas características do ensino parisiense. $\mathrm{O}$ modus parisiensis era um modelo marcado pela coerência, pelo rigor e também pela eficácia, além disso era um modelo que dava especial relevância à ordem e disciplina para a aprendizagem, características que acabavam por ir ao encontro da própria personalidade jesuítica. Ademais, o modelo configurava-se fundamentalmente por quatro características principais, quais fossem, "a distribuição dos alunos em classes, uma actividade constante dos alunos através de exercícios escolares, um regime de incentivos ao trabalho escolar, e a união da piedade e dos bons costumes com as letras" (SCOPINHO, 2010, p. 31, nota de rodapé).

Trata-se de uma importante mudança nas práticas do Colégio, lembrando que, como mencionamos, quando Francisco Xavier chegou pela primeira vez ao Seminário de Santa Fé, declarou que os estudantes apenas sabiam ler e escrever, faziam exercícios de repetiçóes etc... Parece-nos que a primeira mudança significativa nos modos de ensinar no Colégio foi mesmo essa empreendida por António Gomes. Entretanto, o correspondente mencionado anteriormente, o padre Lancelote, não parecia particularmente confiante nos resultados que viriam de tais mudanças. Logo em seguida ao trecho anteriormente transcrito, o padre acrescenta que "Con l'aiuta de Dio farà tutto [...]". Seria normal, na escrita de um padre, uma menção à ajuda de Deus, uma expressão própria do dia a dia do clérigo, mas, na continuidade da frase, está assim escrito:

[...] ancorachè dificilmente perchè questa gente che sta in questo colegio è uma coletta fatta de diece natione, uma più barbara che l'altra, le più barbare et inculte generatione che siano nella terra, de manera che tutto quello che qui io podria scrivere restarà per examinare alla prudentia de V. R., perquè a bono intendidoro poche parole bastano. (LANCELOTE, 1548, s.p. Apud WICKI, 1948, p. 439-440)

Subentendemos que o padre Nicolau Lancelote, particularmente, não acreditava no sucesso das reformas de António Gomes. O padre Lancelote conhecia bem o Colégio e seus estudantes, sendo que fora reitor nesse Colégio até a chegada de António Gomes. Ao dizer que, "Com a ajuda de Deus fará fruto, ainda que dificilmente” (GOMES, 1548, sp.), o padre mostra como não acredita que uma formação mais intelectualizada e espiritual, aos moldes do modus parisiensis, teria 
sucesso para os estudantes nativos. Isso fica especialmente visível ao escrever para Loiola que "[...] tudo aquilo que eu poderia escrever restará a examinar a prudência de Vossa Reverendíssima, porque ao bom entendedor poucas palavras bastam"! (LANCELOTE, 1548, s.p.). Lancelote queria escrever dizendo que a reforma não daria certo, entretanto, ao invés de escrever diretamente, deixou a afirmação em aberto para Loiola. Talvez a disciplina jesuítica, seus modos de trabalhar, seu sentimento de corpo único e, sobretudo, seu forte sentimento de hierarquia não tenham permitido ao padre Lancelote escrever, naquele momento, literalmente, tudo o que pensava sobre as atitudes do novo reitor.

Temos a oportunidade de ler algumas impressões que António Gomes tinha sobre o Colégio e sobre o próprio trabalho em carta escrita de Goa a Inácio de Loiola em 25 de outubro de 1549 (GOMES, 1549, s.p. Apud WICKI, 1948, p. 517-523). Queremos trazer um excerto da missiva, em que o padre dá ao Geral um resumo daquilo que vinha sendo feito na instituição.

Estamos aqui vynte e tantos Irmãos da Companhia. Os moços da terra saam muitos e estam à parte. Os mais dos Yrmãos começam agora d'aprender gramatica. Tem já andado em oficios, e, exercitados, dan-se muito à oraçam. Espero en Deus que antes de muito tempo sejam para fructificar: ay boons engenhos e abelidades, e os mais saam de nobre casta. (GOMES, 1549, s.p. Apud WICKI, 1948, p. 522, grifos nossos)

Em linhas gerais, parece que o reitor estava satisfeito com os trabalhos iniciais a que submetia o Colégio sob sua liderança. A menção aos moços da terra, “[...] que são muitos e estão à parte [...]” (GOMES, 1549, s.p.) dos primeiros mencionados, os irmãos da Companhia, indicá-nos que a essa altura já havia uma divisão interna dos estudos e das finalidades do Colégio: uma delas era, ainda, a inicial vocação do Seminário de Santa Fé de formar os nativos para o sacerdócio, e, então, havia outra, mais especificamente ligada ao Colégio de São Paulo, que era a de formar os membros da Companhia, os irmãos que depois viriam a ser padres da Companhia de Jesus.

Outra questão a ser destacada é a menção que se fazia sobre os naturais da terra que, segundo o padre reitor, “[...] são de nobre casta” (GOMES, 1549, s.p.). Boxer já mostrou que, para a formação do clero secular na Índia, havia a preferência por aqueles que pertencessem às castas superiores, pois eles eram, via de regra, escolhidos “[...] entre os brâmanes (como os Portugueses lhes chamaram), mais ou menos convertidos pela força, e, ocasionalmente, entre os xátrias ou casta guerreira”. Não obstante, o autor ainda aponta que "[...] a maior parte das autoridades eclesiásticas e seculares portuguesas não confiava neles [...]” (BOXER, 2013, p. 22). No caso de António Gomes, veremos que seu "preconceito" - usando um termo empregado por Boxer (2002, p. 262) - estendia-se inclusive além dos parâmetros demonstrados pelos demais eclesiásticos de seu tempo. Ainda que Xavier admitisse que os portugueses na Índia jamais aceitassem confessar ou receber os ofícios eclesiásticos de clérigos nativos, o mesmo não contestava a possibilidade de que esses nativos atendessem a suas populações autóctones. António Gomes mostrou-se algumas vezes reticente mesmo a essa possibilidade.

Gomide (2016) mostra-nos que os critérios de "pureza de sangue", inseridos no ideário da sociedade lusa, refletiam-se nas relações sociais e hierarquias dos espaços coloniais. Boxer (2002, p. 262) afirma que os conceitos de "limpeza" e "pureza de sangue", bem como expressóes como "raças infectas" estiveram presentes "em documentos oficiais e na correspondência privada até o último quartel do século XVIII”. Para ilustrar o nível de "preconceito” do padre Gomes, e, para afirmar que sua resistência aos nativos pode ser diretamente ligada ao ideário de "pureza de sangue", 
apontamos que, à ocasião da nomeação do padre Henrique Henriques como superior jesuíta na Costa da Pescaria, Gomes posicionou-se contra, pelo fato de o padre Henriques ter ascendência judaica. Santos afirma que "Henrique Henriques foi eleito superior regional na Pescaria (Costa da Pescaria, pertencente à Província de Goa), apesar do jesuíta António Gomes ter sido contra sua eleição alegando sua ascendência judaica. Entretanto, ocupou o cargo entre 1549-76" (SANTOS, 2007, p. 47). Corroborando a ideia, veremos à frente que, ao proceder a expulsão de vários rapazes naturais da terra, António Gomes instituiu uma completa separação entre os nativos que restaram e os portugueses no Colégio.

Com relação à ordenação de padres na instituição, temos relato do ano de 1549 , feito pelo padre jesuíta Baltazar Gago, em carta escrita aos irmãos da Companhia de Jesus em Coimbra, datada de outubro do mesmo ano (GAGO, 1549, s.p. Apud WICKI, 1948, p. 548-570). O relato fala-nos do recebimento de "irmãos" no Colégio e menciona algumas ordenações: entretanto não são essas ainda de padres nativos, mas de europeus. Vejamos o seguinte excerto:

Los Hermanos recebidos en este collegio hasta el presente, después que vino el P. Antonio Gómez (que dantes no se recebían), son 20; destos fueron 2 al Cabo de Comorín y uno fué a Coulam al P. Nicolao, otros 2 a Basaín, los más están aquy en este collegio. Destos se ordenaron dos de missa a la fechura desta; este domingo paseado a 12 de Octubre, disse uno dellos missa nova por nombre Domingos de Carvallo, el otro es Francisco López, y a de dizir missa dia de las 11.000 Vírgines: Fueron ordenados en este collegio em 3 domingos por el Obispo. Entre estos Hermanos a grandes abilidades y deseos de padecer por el Señor. Estudian al presente Andrés de Carvallo, Álvaro Ferrera, Melo, Francisco de la Silva, Reymão Perera, Barreto, Araújo, Francisco López; de manhã, meditan, antes de jantar examen, al mediodía repiten las lectiones: los otros andan en officios de casa y dos están en los Exercícios. (GAGO, 1549, s.p. Apud WICKI, 1948, p. 567-569)

Os irmãos aqui mencionados são irmãos da Companhia de Jesus. Como informa Francisco Rodrigues, aqueles que não fossem recebidos em colégios da Companhia na Europa poderiam tentar ser recebidos no Colégio de Goa (RODRIGUES, 1931). Percebamos que o padre Baltazar destaca que o recebimento de irmãos da Companhia para formação não acontecia antes de António Gomes, sendo essa uma das mudanças que o padre reitor empreendera. Com o governo de António Gomes, a instituição passou a ser, além de um lugar para formação de nativos, um colégio para formação de quadros para a Companhia de Jesus.

Mais detalhes sobre as atividades e as mudanças empreendidas pelo reitor António Gomes são trazidas em outra carta do padre Nicolau Lancelote para Inácio de Loiola. Lancelote, que havia sido também reitor do Colégio por curto espaço de tempo, antes da chegada de Gomes, escreve ao Geral em 25 de janeiro de 1550, estando em Coulão (LANCELOTE, 1550, s.p. Apud WICKI, 1950, p. 08-13).

$\mathrm{Na}$ carta, padre Lancelote conta a Loiola que o padre António Gomes fora enviado inicialmente para chefiar tanto o Colégio de São Paulo quanto os demais padres da Companhia na Índia, durante as ausências de Xavier. Isso teria sido feito por Simão Rodrigues, provincial português da Companhia, a pedido do padre Lancelote, que, segundo seu próprio relato, não se considerava apto a ter o cargo de reitor do Colégio e chefe dos jesuítas: 
Dopo che io importuna[i] molto el Padre Maestro Simone che me tirasse el cargo, che io indignamente teneva delli nostri che qua erano, feceme la gratia c mandò el Doctore Antonio Gomes l'anno passato con grande provisione, che fosse qua Superiore de tutti noi altri, el quale certamente niiuno o recusava, ma tutti o recevevano como era rascione; [...]. (LANCELOTE, 1550, s.p. Apud WICKI, 1950, p. 10)

O fato de António Gomes chefiar os jesuítas da missão, mesmo que apenas durante as ausências de Francisco Xavier, parece não ter sido uma boa experiência, pois, segundo Lancelote, Xavier precisou retirar-lhe essa responsabilidade, deixando-o apenas como reitor do Colégio, e não mais como superior dos padres jesuítas.

[...] ma lui entrò nel cargo con tanto fervore e con tanta austerità, che foi neccessario che Maestro Francesco remediasse. El rimedio che dette a questo foi che Antonio Gomes non tenesse cargo de noi altri; ma poichè lui era grato e accetto al populo de Goa per le sue predicatione e così per intercessione del populo, mandò Maestro Francesco che Antonio Gomes tinesse cargo de quello collegio de Santa Fe e che predicasse in quella cità fin tanto che vinisse nova provisione da Roma o da Portugallo [...]. (LANCELOTE, 1550, s.p. Apud WICKI, 1950, p. 10) ${ }^{4}$

Vejamos que Xavier, no relato de Lancelote, apenas mantinha António Gomes como reitor do Colégio por conta do prestígio que aquele tinha junto à população de Goa. Sendo assim, Gomes não mais ficava como superior dos jesuítas, mas ainda detinha o comando do Colégio. Àquela época tratada por Lancelote - logo que António Gomes assumiu o governo do Colégio - a instituição ainda não tinha estudantes portugueses nem europeus. Seguindo no relato do padre Lancelote, leremos que "[...] nel quale collegio non stavano se no tanti scolari indii, per doctrina et favore delli quali foi instituito e ordenato quello colegio" (LANCELOTE, 1550, s.p. Apud WICKI, 1950, p. 10). Entretanto, convencido de que os colegiais nativos não teriam capacidades acuradas para espiritualidade e aprendizagem como os portugueses, o reitor Gomes intentou expulsar todos os nativos do Colégio. Vemos, ainda, no relato de Lancelote, que houve resistências a Gomes nesse sentido, resistências estas que o teriam em parte impedido de cumprir totalmente seu intento, mas que não foram capazes de impedi-lo por completo. Assim, mandou embora 27 estudantes nativos do Colégio e admitiu portugueses em seus lugares, a fim de formá-los para a Companhia - indo essa informação ao encontro do que foi contado pelo padre Baltazar Gago na carta anteriormente citada. É válido lermos na íntegra como Lancelote descreve o acontecido:

[...] ma perchè questi scolari sonno de diverse natione, piú barberi de quello che se poscrivere e non se possono tan facilmente fare abili e capaci delle virtú della devotione e contemplatione como li altri, [...] Antonio Gomes, dopo de lui tenere la ministratione del collegio in mano, lhe parse bene mandar fore li indii e fare un collegio de portuguesi, cio è della Compagnia, la qual cosa pose per opera in grande parte. Se certe persone che possevano e devevano non resistivano, già li indii seriano tutti fore e con tutta la resistentia, che glhe foi fatta, mandò fore vinti e sette delli indii et recevette altri tanti portuguesi per la Compagnia [...]. (LANCELOTE, 1550, s.p. Apud WICKI, 1950, p. 10)5

O padre Lancelote parece até mesmo concordar com Gomes ao considerar os nativos "inferiores” aos portugueses no que concerne à “espiritualidade", “contemplação" e "devoção”. Entretanto, o Seminário de Santa Fé, instituição da qual se formou o Colégio de São Paulo, fora entregue à 
Companhia, lembra Lancelote, para formação de nativos, "[...] per doctrina et favore delli quali foi instituito e ordenato quello colegio” (LANCELOTE, 1550, s.p. Apud WICKI, 1950, p. 10). O princípio norteador da fundação do Colégio - ainda que com boas argumentaçóes - estava sendo aqui rescindido e sem consulta ou mesmo informação prévia à autoridade jesuítica na Índia, que seria o provincial, Francisco Xavier.

Apesar de não ter conseguido realizar por completo seu intento, que seria a expulsão de todos os nativos do Colégio, o reitor ainda, assim, imprimiu um novo modelo de trabalho, ao que nos mostra a carta de Lancelote. O padre prossegue contando que, segundo carta que teria recebido do Colégio, os alunos portugueses recebidos por Gomes estavam "[...] se exercitano in mortificatione e devotione [...]", começavam já a aprender Gramática e iam em "grande fervore”. Por sua vez, os nativos, “[...] perchè non tengono fervore [...]”, estavam separados dos portugueses, com os quais sequer se comunicavam: "[...] tengono refertorio e dormittorio e la serventia e conversatione de casa, tutta separata la da una parte”. Evidentemente que a decisão do reitor António Gomes causou desconforto, inicialmente nos colegiais nativos que ficaram na casa, os quais "[...] della qual cosa loro se atristano et disconsolano non poco" (LANCELOTE, 1550, s.p. Apud WICKI, 1950, p. 10-11). Lancelote pede, de certa forma, atenção de Loiola para o caso. Como afirmamos já anteriormente, vemos nessa carta também, implícita, a total discordância de Lancelote com a política adotada por António Gomes. De forma comedida, como jesuíta conhecedor e cumpridor da hierarquia, Lancelote pede implicitamente a intervenção de Loiola, sem de fato pedi-la.

Temos, então, no início de 1550, o Colégio de São Paulo, em meio a uma radical mudança: em lugar de haver apenas nativos, 27 destes foram expulsos, foram recebidos em seu lugar outros vinte portugueses para estudarem e formarem-se clérigos para a Companhia de Jesus, e o Colégio viveu um período de educação e formação mista, porém separada: de um lado, foram formados os nativos que restaram; de outro, europeus, para serem jesuítas. Souza comenta o acontecimento, mostrando também como Gomes, ao seu reitor, havia decidido "[...] expulsar uns 27 rapazes naturais e substituí-los por europeus, porque se tinha convencido de que os naturais não tinham qualidades para a 'contemplação e devoção' [...]” (2000, p. 122).

A população de Goa, em geral, e também Francisco Xavier, não parecem ter recebido bem as mudanças profundas e repentinas empreendidas por António Gomes, e a reversão delas aconteceu apenas com a chegada de um novo vice-rei na Índia: D. A fonso de Noronha. Podemos afirmar isso com base em uma carta escrita pelo próprio vice-rei. Estando em Cochim, D. Afonso de Noronha escreve ao provincial português da Companhia de Jesus, padre Simão Rodrigues, em carta datada de cinco de janeiro de 1551 (NORONHA, 1551, s.p. Apud WICKI, 1950, p. 138-143).

Em sua carta, o vice-rei começa por elogiar a Companhia, dizendo "Achey a terra muy contente da Companhia e que fazem nella tanto fruito, que hé pera muyto louvar a Nosso Senhor, e hé quasi como o que os Apostolos fizerão em seu tempo [...]”, para, em seguida, prosseguir escrevendo a Simão Rodrigues como estava "sob sua obediência" e que se considerava como que parte da Companhia e que justamente por isso se considerava "[...] obrigado a dizer tudo o que me parecer que hé necessario pera bem e conservação della” (NORONHA, 1551, s.p. Apud WICKI, 1950, p. 140). É na sequência que o vice-rei mostraria ao provincial a situação que ele considerava "ruim" para a Companhia de Jesus.

D. Afonso de Noronha diz a Simão Rodrigues que o povo da terra andava escandalizado com o padre reitor António Gomes por duas razóes. A primeira era a amizade do padre com o 
governador anterior, Jorge Cabral: segundo o relato de D. Afonso, tão próximos eram o reitor e o governador que o povo começou a confundir as ações de Jorge Cabral com as do padre reitor, culpando o último por coisas feitas e decididas pelo primeiro. A esse respeito, D. Afonso afirma que não via culpa em António Gomes (NORONHA, 1551, s.p. Apud WICKI, 1950, p. 140).

Entretanto, sobre a segunda razão, o vice-rei não faz defesa do padre: a cidade de Goa estava “escandalizada dél”, por conta da expulsão dos nativos do Colégio. Nas palavras de D. Afonso,

[...] un dia, sin parecer del Obispo ni de ninguna otra persona secular, solamente con consintimiento de Jorge Cabral echó Antonio Gómez todos los muchachos fuera del collegio, y amanesció el otro dia tan solo, como la tierra en que mueren de peste. (NORONHA, 1551, s.p. Apud WICKI, 1950, p. 140)

Sem consultar o bispo ou outros padres, nem quaisquer autoridades civis da cidade, apenas com o consentimento de D. Jorge Cabral, o reitor expulsou vários ${ }^{6}$ meninos nativos do Colégio, o que causou grande espanto, e porque não dizer, revolta na cidade: "Con tan gran novedad fué tanto el espanto em Goa, como la cosa requeria” (NORONHA, 1551, s.p. Apud WICKI, 1950, p. 140-141).

$\mathrm{O}$ bispo teria falado ao padre Gomes que voltasse a recolher os meninos nativos, ao que ele se teria negado:

Habló el Obispo y otros cavalleros a Antonio Gómez que los tornasse a recoger. Nunqua lo quiso hazer, diziendo que no queria tener en el collegio, sino muchachos portugueses que él para esso buscaria. Quando yo aqui llegué, en la mar me hizieron desto sabidor [...]. (NORONHA, 1551, s.p. Apud WICKI, 1950, p. 141)

Resumindo a situação, D. Afonso relata que havia encontrado "[...] esta ciudad en demanda con Antonio Gómez [...]” (NORONHA, 1551, s.p. Apud WICKI, 1950, p. 141).

Como justificativa, António Gomes afirmou que despedira os meninos nativos por acreditar que neles não haveria o desenvolvimento necessário - “[...] se no podía hazer fruto [...]” - e que, ainda, havia achado alguns "culpados en graves peccados". O vice-rei, discordando da primeira justificativa do reitor, ordenou que apenas os tais "pecadores" pudessem ser despedidos, mas que o propósito inicial do Colégio - servir para formar nativos - só poderia ser mudado perante ordem do rei, pois "[...] el dinero que S. A. dava para se gastar en esta obra, no se podia aplicar a otra sin su mandado" (NORONHA, 1551, s.p. Apud WICKI, 1950, p. 141-142).

O Colégio deveria voltar à sua normalidade, ordenando o vice-rei que

[...] él tornase luego a mandar poblar el collegio de los niños christianos de la tierra; y los mandasse enseñar a leer, escrevir, rezar y latin; y tanto que fuessen de edad de XV anos, [...]. Pareció a todos y a él muy bien, y púsose luego en orden. (NORONHA, 1551, s.p. Apud WICKI, 1950, p. 142)

Parece-nos que a normalidade foi então retomada, pois o vice-rei afirma ainda que "[...] del Cabo de Comory llegaron aora aqui XIIJ [13] niños, y de Baçayn vienen algunos, y daqui [Cochim] levarán tanbién algunos; y dizen los Padres que, quando yo llegare a Goa, allaré en el collegio de 40 niños para cima” (NORONHA, 1551, s.p. Apud WICKI, 1950, p. 142). Corrobora o relato a carta escrita a Inácio de Loiola pelo padre Nicolau Lancelote, estando em Coulão, a seis de janeiro 
de 1550, em que o padre conta ao Geral todo o caso da expulsão, dizendo que o Colégio já havia voltado a receber meninos nativos e que ele mesmo já havia mandado quinze nativos de Coulão para Goa, a estarem no Colégio (LANCELOTE, 1551, s.p. Apud WICKI, 1950, p. 148).

Ainda reitor do Colégio de São Paulo, António Gomes escreve a Inácio de Loiola em dezesseis de janeiro de 1551, estando em Cochim (GOMES, 1551, s.p. Apud WICKI, 1950, p. 174-180). Parece-nos ser possível afirmar que o padre Gomes era um homem de forte personalidade, certo de suas convicções: mesmo após os reveses sofridos em sua tentativa de reorganização do Colégio, o padre seguiu com os mesmos ideais na carta ora mencionada. Nela, ele informa ao Geral que havia no Colégio trinta irmãos - referindo-se a europeus candidatos a padres da Companhia - os quais seguiam regimento "com’o do colegio de Coimbra”. Entretanto, lamenta-se o reitor, que “[...] há muita mimgoa de pessoas que posamos receber pera a Companhia, porque os espanhoes e portugeses sam pouquos, e caje não há nenhuns que tenhão talemto pera emtrar na Companhia [...]” (GOMES, 1551, s.p. Apud WICKI, 1950, p. 176). Vemos na escrita do reitor que seu projeto era, essencialmente, formar quadros para a Companhia de Jesus, o que o tornava, consequentemente, desinteressado pelo projeto inicial do Colégio que agora dirigia, que era formar um clero nativo. Isso não quer dizer que não houvesse projetos de formar jesuítas no Colégio de São Paulo: essa intenção existia, segundo podemos ver num alvará de vinte de fevereiro de 1551, em que D. João III doava "em perpétuo" os Colégios de Goa e Baçaim à Companhia de Jesus. Uma das justificativas do alvará régio era justamente a de que os colégios serviriam para formação de padres para a Companhia, visto, segundo escrito no documento, a impossibilidade de mandar do reino tantos jesuítas quantos seriam necessários para a missão indiana (D. JOÃO III, 1551, s.p. Apud WICKI, 1950, p. 189-193). Outro documento a corroborar isso é uma carta do padre jesuíta Ludovico Gonçalves da Câmara, escrita a Simão Rodrigues, de Almeirim, em quatorze de março de 1551. Na carta, padre Ludovico fala sobre a partida de alguns jesuítas para a Índia, dizendo ir com eles seis moços com a intenção de estudar no Colégio de Goa, certamente aspirantes à Companhia (Gonçalves, 1551, s.p. Apud WICKI, 1950, p. 194-197). O fato de haver projetos de formação de jesuítas em Goa não significa que um objetivo pudesse ser priorizado em detrimento do outro. Ou seja, o Seminário de Santa Fé e o Colégio de São Paulo deveriam formar, concomitantemente, clero secular nativo e clero regular jesuíta.

A visão de António Gomes e seu projeto de priorizar a formação de jesuítas certamente foram determinantes para o desprezo com o qual tratou a outra face do trabalho, qual fosse, a formação dos nativos. Estes não interessavam ao padre, que os considerava, por óbvio, totalmente inaptos para o ingresso na Companhia, e que talvez considerasse mesmo para o desempenho do sacerdócio secular. Vemos isso na sequência de sua carta, quando o reitor fala a Loiola sobre a não possibilidade de recrutamento para a Companhia entre os indianos:

[...] nem dos da terra me parece que se pode aumemtala a Companhia por serem mui fraquos na ffee e, aimda que aja muita elleição, não creo que se acharão alguns pera iso, pola esperiemcia que se tem quá diso; e, se se ouverem de criar de meninos e acustumar a bons custumes, alem desta ocupação ser trabalhosa, porque os que tiverem superemtemdemcia sobre elles poderam noutras obras de mais serviço de Deus emtemder, hé periguo que muy pouquos ou nenhuns sejão abeles pera a Companhia [...]. (GOMES, 1551, s.p. Apud WICKI, 1950, p. 176). 
O fato de António Gomes não considerar os nativos para ingresso na Companhia não é estranhável, nem mesmo dissonante de outras opinióes à época - o próprio Francisco Xavier também não defendia a possibilidade de tomar indianos para a Companhia. Como já mostrado anteriormente, de início as ordens de modo geral não recebiam nativos indianos em suas fileiras, posição também acompanhada pela Companhia de Jesus. No entanto, o fato de considerar os nativos inaptos à vida religiosa exacerbou-se na pessoa de António Gomes, fazendo com que ele representasse, naquele momento, um risco para o trabalho de formação de clero indígena empreendida custosamente - considerando custos financeiros e de pessoal -, desde 1541, pela Confraria de Conversão à Fé, e certamente isso não seria permitido pelo vice-rei, nem mesmo por Xavier. Indício de sua insistência no projeto de despedir os nativos do Colégio também foi dado quando, na carta citada, o reitor pede algumas orientações gerais a Loiola, entre elas:

[...] por que caso se poderá despedir hum, porque vejo não á cousa mais necesaria, que botarem-se aqueles fora que fazem nojo a si e a muitos; nisto folgaria muito V. R. ser muy meudo, porque às vezes tenho scrupulo de botar alguns fora e tambem de hos sofrer na Companhia, pólo pouquo proveito que fazem em si e algum nojo nos outros. (GOMES, 1551, s.p. Apud WICKI, 1950, p. 177).

Mesmo após as determinações do vice-rei, a retomada de meninos nativos e a "normalização" dos trabalhos, o padre reitor ainda deseja, vinda de Loiola, uma instrução para dispensa de estudantes. Além disso, pede ao Geral que seja "muy meudo" em tal descrição. Podemos inferir que o que Gomes desejava era, em síntese, um subterfúgio para proceder a suas expulsões: afinal, se ele, o reitor, tivesse em mãos uma instrução vinda diretamente do Geral, Inácio de Loiola, e apoiasse-se nela para, então, expulsar os nativos do Colégio, nem o vice-rei, nem os demais padres da casa, nem mesmo o provincial Francisco Xavier, poderiam contestar suas açóes.

António Gomes parece não ter tido tempo, nem chance, como reitor, de receber a resposta de Inácio de Loiola. Em carta escrita ao mesmo Geral, em doze de dezembro de 1551, vemos o jesuíta Gaspar Barzeo informar:

Vindo de Urmus, chammado polo Padre Mestre Francisco pera Japão, hachei quá ho Padre Micer Paulo substituido por Reitor deste collegio de Guoa, na desistentia do Padre Antonio Gomez que dantes fora Rector, e esto por voz de todo los Yrmãos de casa, sem embarguo de ser acheiguado houtro de Purtugal polo Padre Mestre Simão por Provincial, que se chamma ho Padre Belchior Nunnez, hò qual não quizerão obedecer hata vir requado de Japão do Padre Mestre Francisquo, dizendo-me que esta hera ha entenção delle, não dar a nenguem ho careguo hata ser experimentado na sua sufficientia por algum tempo. (BARZEO, 1551, s.p. Apud WICKI, 1950, p. 242).

Havia chegado ao fim o governo do reitor António Gomes. Sem conseguir cumprir seus intentos e, a crermos na documentação, desacreditado e desautorizado perante seus confrades e mesmo pela população de Goa, teria o padre Gomes “desistido” do cargo de reitor. Souza (2000, p. 122) nos diz que o padre Gomes foi "forçado" por Xavier a sair do cargo de reitor, da Companhia de Jesus e, ainda, da Índia. Segundo Souza, "Francisco Xavier não o considerava apto para ser um bom superior segundo o espírito inaciano. Um reitor deveria ser um pai que governa, que seja capaz de combinar severidade com benignidade, e não um chefe que comanda”. Ainda, conforme o mesmo 
autor, o padre Gomes foi chamado a Roma por Loiola para explicar ao Geral suas posições, mas não chegou lá, tendo morrido a caminho da Europa, em 1554, no naufrágio da nau "São Bento".

Queremos chamar a atenção, ainda, para o trecho final do excerto, que trouxemos anteriormente, da carta do padre Barzeo a Loiola. Na suposta "desistência” de António Gomes ao cargo de reitor, os jesuítas do Colégio "elegeram” para o cargo Micer Paulo, não obstante haver chegado de Portugal o padre Belchior Nunes, mandado por Simão Rodrigues para ser superior nas ausências de Xavier. Ao contrário de acatar prontamente a autoridade do padre Belchior, mandado pelo provincial português, os jesuítas decidiram apenas o fazer sob o mandado de Xavier, denotando certa cisão dos costumes, muito provavelmente ocorrida pela má experiência com António Gomes. Visto que Gomes fora também mandado por Simão Rodrigues e prontamente recebido pelos jesuítas, seria natural receberem também, da mesma forma, o padre Belchior. A experiência com António Gomes parece ter deixado algumas impressóes profundas naqueles padres, que não estavam dispostos a se arriscar de novo, sem antes consultarem o provincial em que confiavam, Francisco Xavier. Esse argumento pode ser substanciado por outro trecho da mesma carta, em que Barzeo descreve a Loiola aquelas que considera serem condiçóes para o bom andamento das missões na Índia. Entre elas, o padre anota que:

[...] hos que quá houverem de residir por Provinciaes, não se devem de reger soos por suas cabeças, como hataguora fazem, mais antis se devem de aconcelhar com hos antiguos na Ymdia, da Companhia e perfectos, e sem seu concelho não fazer nada. Isfo entendo nas cousas que emportão à Companhia, pera evitar muitas cabeçadas que algumas vezes dão com muito scandalo da Companbia e povo, por honde ho fervor do collegio se perde e ho fruto no povo. (BARZEO, 1551, s.p. Apud WICKI, 1950, p. 243, grifos nossos).

A experiência com António Gomes certamente deixou marcas, como mostra a crítica - nem tão - velada, feita pelo padre Barzeo.

Como indica a historiografia aqui relacionada, o problema dos cleros indígenas não foi exclusivo do Oriente Português, encontrando também expressão em outros espaços coloniais, como nas colônias portuguesa e espanhola na América. O tema é amplo, e os limites do presente trabalho impedem-nos de abordar as tensões nesses demais espaços. Entretanto, o exemplo aqui trabalhado nos auxilia na compreensão de uma parte dessas tensões, nomeadamente aquelas presentes na Índia Portuguesa.

\section{Considerações finais}

O Colégio de São Paulo, em Goa, foi fundado pelos jesuítas a partir do Seminário de Santa Fé, instituição iniciada pelos confrades da Confraria de Conversão à Fé, destinada à educação e formação de um clero autóctone da Índia. Várias doações e concessões régias foram, ao longo do tempo, feitas à instituição, visando sempre à finalidade para a qual havia sido criada.

Os primeiros jesuítas a participarem dos processos de educação e formação no Seminário de Santa Fé parecem ter compreendido e aceitado o projeto da instituição, dando continuidade a ele mesmo depois de fundado o Colégio de São Paulo. Destoou dessa visão o padre António Gomes que, enviado de Portugal para ser reitor do dito Colégio, intentou e implementou a expulsão de 
nativos e sua substituição por europeus, visando a usar o Colégio de São Paulo mais amplamente para a formação de quadros qualificados para a Companhia de Jesus.

Entretanto, amparado pelo propósito inicial da instituição - a formação do clero nativo - vemos que o projeto de António Gomes não prosperou. Suas ações foram quase totalmente revertidas, e o padre, desamparado pelas autoridades civis e religiosas locais, viu-se obrigado a abandonar o cargo de reitor e a própria Companhia de Jesus. Morreu sem a oportunidade de explicar-se perante o Padre Geral, Inácio de Loiola.

Entendemos a presença da Igreja como parte do projeto colonizador português. Indubitavelmente, o objetivo português era impor sua cultura e sua religião - ainda que compreendamos a mistura, o encontro cultual que houve naquelas partes. Assim, vemos que a fundação de um seminário exclusivo para formar nativos tinha como objetivo formar agentes de disseminação da cultura portuguesa. $\mathrm{O}$ fato de vislumbrar-se a formação de um grupo nativo, instrumentalizado na cultura e na religião portuguesas e pregando para seus iguais, certamente deixaria o cristianismo e mesmo a cultura lusa mais aceitável para os nativos. O fato de haver um igual levando a eles a "palavra", a "verdade" certamente seria um importante instrumento para a evangelização, a catequese, a cristianização.

Ao impor a expulsão dos nativos do Colégio, António Gomes opôs-se ao projeto que ele representava: projeto esse que já havia sido incorporado e bem aceito pelas autoridades civis e religiosas em Goa e mesmo no Reino. Isso explica o fato de que a tentativa de desvirtuar tais finalidades tenha sido tão mal vista, e de que o projeto do padre Gomes para o Colégio tenha sido derrotado. Ao desfazerem o projeto de António Gomes, o provincial Francisco Xavier e o Governador-Geral D. Afonso de Noronha permitiram a retomada do funcionamento "normal” da instituição, o que desembocou, em 1558, na ordenação do primeiro sacerdote "canarim”, André Vaz.

\section{Referências}

ALBUQUERQUE, Dom João de [Bispo de Goa]. Carta a D. João III. Goa, 5 de novembro de 1548.

ALVARÁ DE D. JOÃO III [rei de Portugal], sobre os colégios de Goa e Baçaim. Almeirim, 20 de fevereiro de 1551.

ANJOS, Camila Domingos dos. “Por Ihe parecer a coisa mais pia e santa de toda Índia”: os jesuítas e a doutrina dos meninos nativos no Colégio de São Paulo em Goa (1541-1599). Anais do 30 Simpósio Nacional de História - ANPUH. Recife, 2019.

BARZEO, Gaspar [Padre]. Carta ao Geral, Inácio de Loiola. Goa, 12 de dezembro de 1551.

BORGES, Felipe A. F. Jesuítas no “Estado da Índia”: o Seminário de Santa Fé e o Colégio de São Paulo em Goa (1541-1558). 256f. Tese (Doutorado em História). Universidade Estadual de Maringá. Maringá. UEM, 2018.

BOXER, Charles Ralph. A Igreja e a Expansão Ibérica (1440-1770). Lisboa: Edições 70, 2013. [Coleção Lugar na História - 11].

BOXER, Charles Ralph. O Império Marítimo Português (1415-1825). São Paulo: Companhia das Letras, 2002.

CÂMARA, Ludovico Gonçalves da [padre]. Carta a Simão Rodrigues, Provincial Português. Almeirim, 14 de março de 1551.

DIAS, Gustavo Nascimento Rocha. O Colégio São Paulo de Goa: os impactos da pedagogia franciscana na prática jesuíta na conversão de nativos na cidade de Goa do séc. XVI. Anais do $30^{\circ}$ Simpósio Nacional de História - ANPUH. Recife, 2019.

FARIA, Patrícia Souza de. Mateus de Castro: um bispo "brâmane" em busca da promoção social no Império Asiático Português (Século XVII). Revista Eletrônica de História do Brasil, v. 9 n. 2, jul./dez. 2007. p. 30-43. 
GAGO, Baltazar [Padre]. Carta aos irmãos da Companhia de Jesus em Coimbra. Goa, entre 14 e 20 de outubro de 1549.

GOMES, António [Padre]. Carta ao padre Simão Rodrigues, provincial lusitano. Goa, 20 de dezembro de 1548.

GOMES, António [Padre] reitor do Colégio de São Paulo. Carta ao padre Inácio de Loiola, Geral da Companhia. Goa, 25 de outubro de 1549.

GOMES, António [Padre] reitor do Colégio de São Paulo. Carta ao padre Inácio de Loiola, Geral da Companhia. Cochim, 16 de janeiro de 1551.

GOMIDE, Ana Paula Sena. Novos encontros, antigos conceitos: hierarquização e (des) qualificação social na Índia portuguesa (séculos XVI-XVII). Temporalidades - Revista de História. Belo Horizonte, v. 8, n. 2, maio/ ago. 2016. p. 24-41.

LACERDA, Teresa. A formação de um clero nativo no Padroado Português (séculos XV-XVIII). Dinâmicas de uma história intercultural? In: LARCHER, Madalena; LANCELOTE, Nicolau [Padre]. Carta ao padre Inácio de Loiola, Geral da Companhia. Cochim, 26 de dezembro de 1548.

LANCELOTE, Nicolau [Padre]. Carta ao padre Inácio de Loiola, Geral da Companhia. Coulão, 25 de janeiro de 1550.

LANCELOTE, Nicolau [Padre]. Carta ao padre Inácio de Loiola, Geral da Companhia. Coulão, 06 de janeiro de 1551.

LONDOÑO, Fernando Torres. Escrevendo Cartas: Jesuítas, Escrita e Missão no Século XVI. Revista Brasileira de História. São Paulo, v. 22, n. 43, 2002. p. 11-32.

MATOS, Paulo Teodoro de (orgs.). Cristianismo e Império: conceitos e historiografia. Lisboa: CHAM - Centro de História d'Aquém e d'Além Mar - Faculdade de Ciências Sociais e Humanas - Universidade NOVA de Lisboa; Universidade dos Açores, 2016. p. 212-243.

NORONHA, D. Afonso de. [Vice-rei da Índia]. Carta ao padre Simão Rodrigues, Provincial lusitano. Cochim, 05 de janeiro de 1551.

PÉCORA, Alcir. Epistolografia Jesuítica no Brasil, Grão-Pará e Maranhão. Revista Estudos Amazônicos, vol. III, n. 1, 2008. p. 39-46.

RODRIGUES, Francisco S. J. História da Companhia de Jesus na Assistência de Portugal. Tomo Primeiro, Vol. II. Porto: Apostolado da Imprensa, 1931.

SANTOS, Robson Luiz Lima. Anti-semitismo na Companhia de Jesus (1540-1593). Tese (Doutorado em História Social). São Paulo: USP, 2007.

SCOPINHO, Marcos Desan. Concepção de estudo presente no Ratio Studiorum. Dissertação (Mestrado em Educação). Piracicaba: Universidade Metodista de Piracicaba, 2010. Disponível em: www.educ.fc.ul.pt/ docentes/opombo/hfe/momentos/jesuitas/_private/mp.htm. Acesso em: 02 ago. 2018.

SOUZA, Teotónio R. de. O ensino e a missionação jesuíta na Índia. In: GONÇALVES, Nuno da Silva. A Companhia de Jesus e a missionação no Oriente: Actas do Colóquio Internacional promovido pela Fundação Oriente e pela Revista Brotéria. Lisboa: Brotéria - Revista de Cultura \& Fundação Oriente, 2000. p. 117-132.

TAVARES, Célia Cristina da Silva. Jesuítas e inquisidores em Goa: a cristandade insular (1540-1682). Lisboa: Roma Editora, 2004.

TAVARES, Célia Cristina da Silva. O clero goês e as estratégias de inserção na hierarquia eclesiástica (século XVII): os casos de Mateus de Castro e José Vaz. In: Anais do XXIV Simpósio Nacional de História - ANPUH. São Leopoldo, 2007.

TAVARES, Célia Cristina da Silva. Clérigos e castas: o clero nativo de Goa e a disputa por cargos eclesiásticos no Estado da Índia - séculos XVII e XVIII. In: MONTEIRO, Rodrigo Bentes; FEITLER, Bruno; CALAINHO, Daniela Buono; FLORES, Jorge (orgs.). Raízes do privilégio: mobilidade social no mundo ibérico do Antigo Regime. Rio de Janeiro: Civilização Brasileira, 2011. p. 567-588.

THOMAZ, Luís Filipe. De Ceuta a Timor. 2. ed. Lisboa: Difel, 1994.

VIEIRA, Antonio. História do Futuro. vols. I e II. Lisboa: Sá da Costa, 1953. 
XAVIER, Ângela Barreto. A invenção de Goa: poder imperial e conversões culturais nos séculos XVI e XVII. Lisboa: Imprensa de Ciências Sociais, 2008.

WICKI, Joseph. Documenta Indica. vol. I. Romae: Monumenta Historica Societatis lesu, 1948.

WICKI, Joseph. Documenta Indica. vol. II. Romae: Monumenta Historica Societatis lesu, 1950.

ŽUPANOV, Inês. Fervors and Tropics: A Jesuit Missionary Career in India (António Gomes, 1548-1554). In: ŽUPANOV, Inês. Missionary Tropics: The Catholic Frontier in India ( $16^{\text {th }}-17^{\text {th }}$ centuries). Ann Arbor: University of Michigan Press, 2005. p. 113-146.

\section{Notas}

1 “[...] e logo que o dito António Gomes entrou no cargo do Colégio começou a dar-Ihe nova forma em tudo, dizendo que queria pôr estes colegiais no estilo parisiense acerca da ordem de estudar, e acerca das meditações e orações na maneira de costume dos nossos em Coimbra, e ao presente leva esta ordem." Tradução própria.

2 “[...] ainda que dificilmente porque esta gente que está neste colégio é uma coleta feita de dez nações, uma mais bárbara que a outra, as mais bárbaras e incultas gerações que estão na terra, de maneira que tudo aquilo que aqui eu poderia escrever restará para exame da prudência de V. R. porque a bom entendedor poucas palavras são suficientes". Tradução própria.

3 “Depois que importunei muito o padre Mestre Simão que me tirasse o cargo, que eu indignamente tinha de nós todos que cá estamos, fez-me a graça e mandou o Doutor António Gomes o ano passado com grande provisão, que fosse aqui Superior de todos nós, o qual certamente ninguém recusava, mas todos o recebemos [...]". Tradução própria.

4 “[...] mas ele entrou no cargo com tanto fervor e tanta austeridade, que foi necessário que mestre Francisco remediasse. O remédio que deu a isto foi que António Gomes não tivesse cargo de nós todos; mas porque era muito aceito pela população de Goa por sua pregação e então pela intercessão da população, mandou Mestre Francisco que António Gomes tivesse cargo do colégio de Santa Fé e que pregasse naquela cidade até que viesse nova provisão de Roma ou Portugal". Tradução própria.

5“[...] mas porque estes colegiais são de diversas nações bárbaras de maneira que não se podem facilmente fazer hábeis e capazes na virtude e devoção e contemplação como nós, [...] António Gomes, depois de ter o controle do colégio em mãos, Ihe pareceu bem mandar fora os indianos e fazer um colégio de portugueses, da Companhia, coisa que pôs em prática em grande parte. Se certas pessoas que podiam e deviam não resistissem, os indianos seriam todos mandados embora e com toda a resistência, que the foi feita, mandou fora vinte e sete indianos e recebeu outros tantos portugueses para a Companhia [...]". Tradução própria.

${ }^{6}$ A carta de D. Afonso de Noronha aqui citada diz que o padre António Gomes teria expulsado "todos" os nativos do Colégio. A maior parte dos demais documentos constantes nas fontes primárias, assim como a historiografia a respeito do caso, são convergentes em dizer que foram alguns, mais precisamente “uns 27 rapazes naturais" (SOUZA, 2000, p. 122). É esse posicionamento que temos aqui seguido. 